\title{
Diversification of land plants: insights from a family-level phylogenetic analysis
}

Omar Fiz-Palacios ${ }^{1,2^{*}}$, Harald Schneider ${ }^{3}$, Jochen Heinrichs ${ }^{4}$ and Vincent Savolainen ${ }^{1,5}$

\begin{abstract}
Background: Some of the evolutionary history of land plants has been documented based on the fossil record and a few broad-scale phylogenetic analyses, especially focusing on angiosperms and ferns. Here, we reconstructed phylogenetic relationships among all 706 families of land plants using molecular data. We dated the phylogeny using multiple fossils and a molecular clock technique. Applying various tests of diversification that take into account topology, branch length, numbers of extant species as well as extinction, we evaluated diversification rates through time. We also compared these diversification profiles against the distribution of the climate modes of the Phanerozoic.
\end{abstract}

Results: We found evidence for the radiations of ferns and mosses in the shadow of angiosperms coinciding with the rather warm Cretaceous global climate. In contrast, gymnosperms and liverworts show a signature of declining diversification rates during geological time periods of cool global climate.

Conclusions: This broad-scale phylogenetic analysis helps to reveal the successive waves of diversification that made up the diversity of land plants we see today. Both warm temperatures and wet climate may have been necessary for the rise of the diversity under a successive lineage replacement scenario.

\section{Background}

It is believed that climate change is one of the main factors affecting global biodiversity [1-3]. During the history of life, fluctuations of the world's climate have most likely caused major extinctions [4] and led to the development of new ecosystems, promoting new biotic interactions and the evolution of novel adaptive traits. The dynamics of such diversification events can be studied based on phylogenetic trees dated with fossils. Here we focus on land plants. The origin and diversification of land plants has intrigued biologists for centuries. According to the fossil record, land plants diverged from green algae before 475 million years ago (Ma; first land plant fossil) and led to the major clades found today $[5,6]$. These are liverworts (74 families, ca. 6,000 spp. [7]), mosses (112 families, ca. 12,000 spp. [8,9]), hornworts (five families, ca. 150 spp. [10]) and tracheophytes. The latter include ferns (45 families, ca. 9,000 spp. [11]), lycophytes (three families, ca. 1,200 spp. [12]), and seed plants, which in

\footnotetext{
* Correspondence: fizpal@gmail.com

'Division of Ecology and Evolution, Imperial College London, Silwood Park Campus, Ascot SL5 7PY, UK

Full list of author information is available at the end of the article
}

turn are separated into gymnosperms (14 families, ca. 1,000 spp. [13]) and angiosperms (456 families, ca. 260,000 spp. [13]).

There are various possible scenarios to describe the processes that influenced land plant diversification throughout geological time. One frequently proposed scenario is based on a successive replacement of ancestral lineages by more derived lineages, which in turn evolved similar habits (e.g., tree-like structure for forested ecosystems), and diversified to fill up the niches left empty after the extinction of the 'previous' taxon. In this kind of scenario, extant taxa of liverworts, mosses, and ferns, are considered to be relicts of previous radiations [14]. An alternative scenario suggests a coincidence between diversification events in each of the extant land plant lineages instead of a 'continuous replacement' idea. In this case, the majority of extant diversity is either the result of recent radiation events or of a long accumulation of species diversity throughout a taxon's history [14]. External factors, such as the break-up of continents and climate fluctuations, are prominent factors influencing the branching of the tree of life.
C Biomed Central

(c) 2011 Fiz-Palacios et al; licensee BioMed Central Ltd. This is an Open Access article distributed under the terms of the Creative Commons Attribution License (http://creativecommons.org/licenses/by/2.0), which permits unrestricted use, distribution, and reproduction in any medium, provided the original work is properly cited. 
In this study we ask two questions: (1) Do we find evidence for non-constant rate of diversification in land plants? (2) Are major shifts of diversification rates, if any, correlated with some major external factors such as global climate warming or cooling?

\section{Results}

We inferred the divergence times of over $98 \%$ of all families of land plants in a single phylogenetic analysis based on multiple genes from two genomes (Additional file 1; TreeBase study ID S11106). The topology and divergence times retrieved from the various analyses are broadly congruent with previous studies with limited sampling [15-17]. All major lineages of land plants as well as the relationships among them were supported (bootstrap support $>74 \%$ ) being mosses (62\%), lycophytes as sister to seed plants (68\%) and hornworts as sister to mosses (47\%) the clades with lowest bootstrap values (TreeBase study ID S11106). This topology is congruent with the analysis using the three most complete markers $(18 \mathrm{~S}$, rbcL and atpB; $6.3 \%$ missing data).

The tree was calibrated using multiple fossils. In one of the calibration procedures, we also constrained the age of angiosperms to a maximum of $130 \mathrm{Ma}$ following Brenner [18] (hereafter the constrained tree). The estimated crown age of land plants was $544.7 \mathrm{Ma}$ (confidence interval $[$ C.I. $]=563.1-536.5)$ and that of angiosperms was 267.6 Ma (C.I. = 289.9-263.2; Additional file 2; TreeBase study ID 11106) whereas for the constrained tree we obtained a crown age for land plants of $510.8 \mathrm{Ma}$ (C.I. = 512.9-475.5).

We produced lineage through time (LTT) plots for both time estimations, presented in Figure 1. These show a roughly constant rate of lineage increase (at least for the family-level studied here), although for angiosperms, ferns and mosses some acceleration is apparent since the Cretaceous, while for liverworts and gymnosperms a slowdown is observed (Figure 1).

A congruent pattern is obtained when we explore the data applying a high level of background extinction using a methodology developed by Magallón \& Sanderson [19]. Figure 2 shows sizes of the major clades against a 95\% confidence interval of background diversification through time for land plants as a whole. In recent times, most clade sizes for mosses (Figure 2C), ferns (Figure 2D) and angiosperms (Figures 2E \&2F, the former being the tree from a constrained analysis) fall above these confidence intervals.

Using a topology-based test of diversification [20], a total of 135 significant rate shifts were identified, with a similar figure found for the constrained tree (139; Table 1). The inclusion of 11 families with no DNA data resulted in the identification of just one more shift in diversification, i.e. on the branch leading to Balanophoraceae. We then explored the concordance of these shifts with the major cool and warm climatic modes [21] and we found some striking correlations. The majority of shifts in diversification rates in angiosperms, ferns, and mosses coincide with the last warm climate mode (Table 1). For liverworts, the highest number of shifts (5) took place in another warm climate mode (184-252 Ma; Table 1). For gymnosperms, only one shift in net diversification occurred, but in this case, during a cool period. This pattern appears to also hold if we compare the timing of shifts in diversification rates with the more continuous global temperature change presented in Scotese [22] (Additional file 3).

Using another diversification test that take into account branch lengths (i.e., LASER [23]), constant rates of lineage diversification were rejected for all major subclades. In gymnoperms, the best model was one with a rate shift occurring ca. $154 \mathrm{Ma}$, corresponding to a decrease in diversification during a cool climate mode (Table 2, Figure $1 \mathrm{~A})$. In the other subclades, two-variable rates were favoured (Table 2, Figure 1A). In angiosperms, two consecutive slowdowns in diversification were identified for the current cool climate mode. In liverworts, a similar pattern was encountered but decreases in rates of diversification occurred firstly in a cool climate mode (ca. 184 $\mathrm{Ma}$ ) and secondly during a warm climate mode (ca. 99 Ma). In ferns and mosses, we first observe two increases in diversification during a cool climate mode (ca. 106 and $133 \mathrm{Ma}$, respectively, Table 2, Figure 1A). Subsequently, two decreases took place $60 \mathrm{Ma}$ (warm mode) for ferns and $35 \mathrm{Ma}$ (cool mode) for mosses (Table 2, Figure 1A). With the constrained tree, the pattern is similar for gymnosperms (Figure 1B, Additional file 4). In the case of angiosperms and liverworts, only one decrease was retrieved about 34 (cool mode) and $99 \mathrm{Ma}$ (warm mode) ago, respectively (Figure 1B, Additional file 4). This pattern is similar to that obtained in the unconstrained tree for mosses and ferns (Figure 1B, Additional file 4), although this time fern diversification increases during a warm mode (ca. $93 \mathrm{Ma}$ ) and decreases during a cool mode (ca. $52 \mathrm{Ma}$; Figure 1B, Additional file 4).

Finally, diversification test incorporating multiple birth and death models as implemented in MEDUSA [24] located 69 diversification rate shifts being the highest overall net diversification rates for different clades within angiosperms (Figure 3, Additional file 5). Among land plants we also found rate shifts leading to high clade-size in mosses and ferns for individual families and clades (Figure 3, Additional file 5). On other hand rates among liverworts and gymnosperms were among the lowest: their background rate were similar to the overall background rate, and their highest rates were lower than most rates found for mosses and ferns (see Additional file 5). Results using the constrained tree were widely congruent (Additional file 5) and a new rate shift for 
A
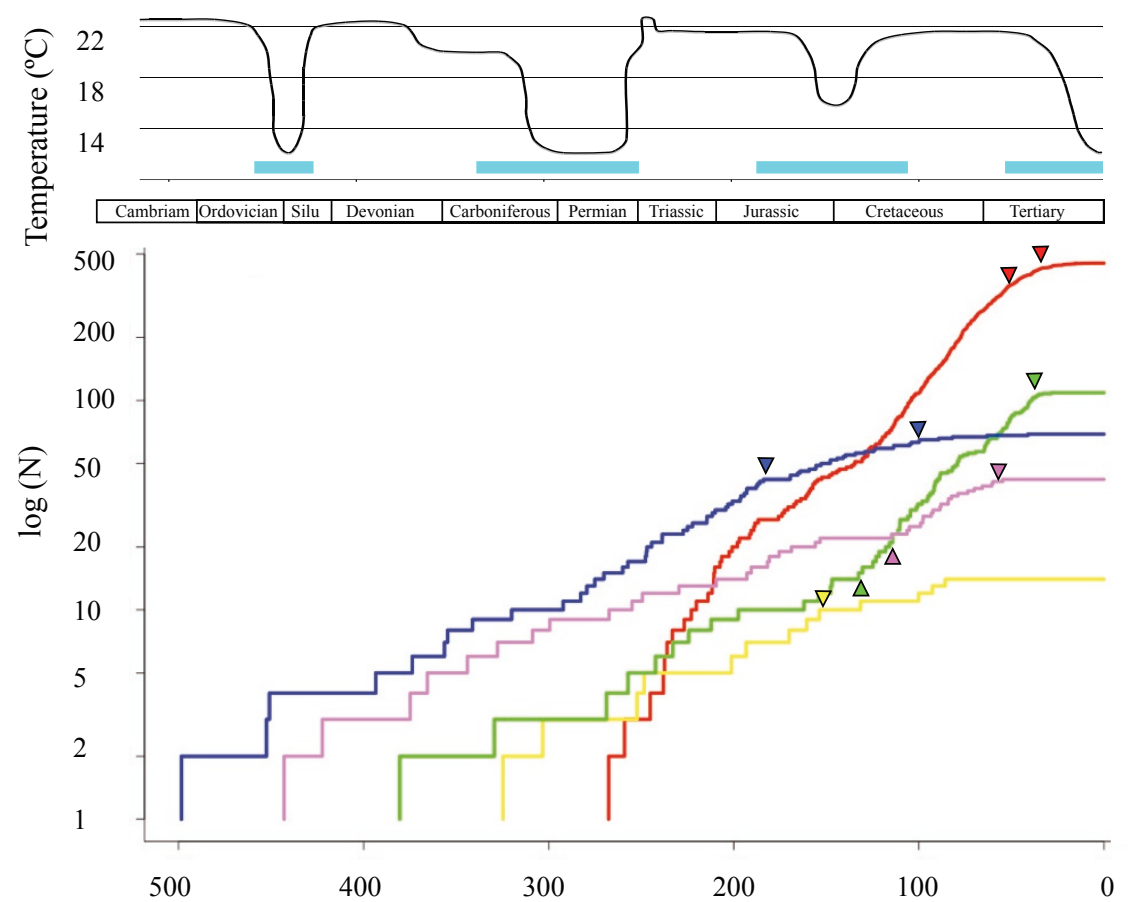

B
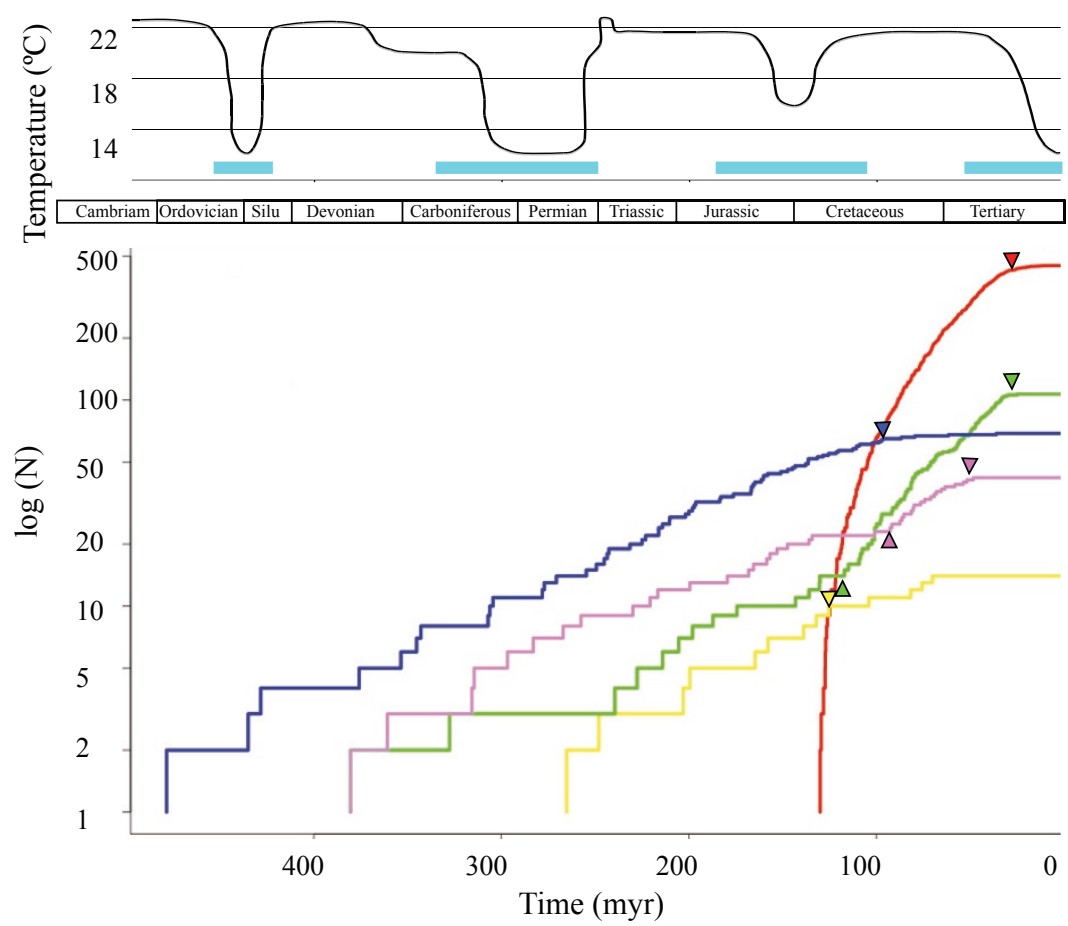

Figure 1 Lineage Through Time plot. Lineage Through Time (LTT) plot for liverworts (blue), mosses (green), ferns (purple), gymnosperms (yellow) and angiosperms (red) with indication of average global temperature [22] and cool climate modes (blue bars [21]). Triangles pointing up or down indicate diversification rate shifts as detected with LASER (increasing or decreasing, respectively, see Methods). (A) unconstrained tree; (B) constrained tree (i.e., angiosperms not older than $130 \mathrm{Ma}$ ). The $\mathrm{y}$-axis indicates the number of lineages $\mathrm{N}$ on a logarithmic scale. 


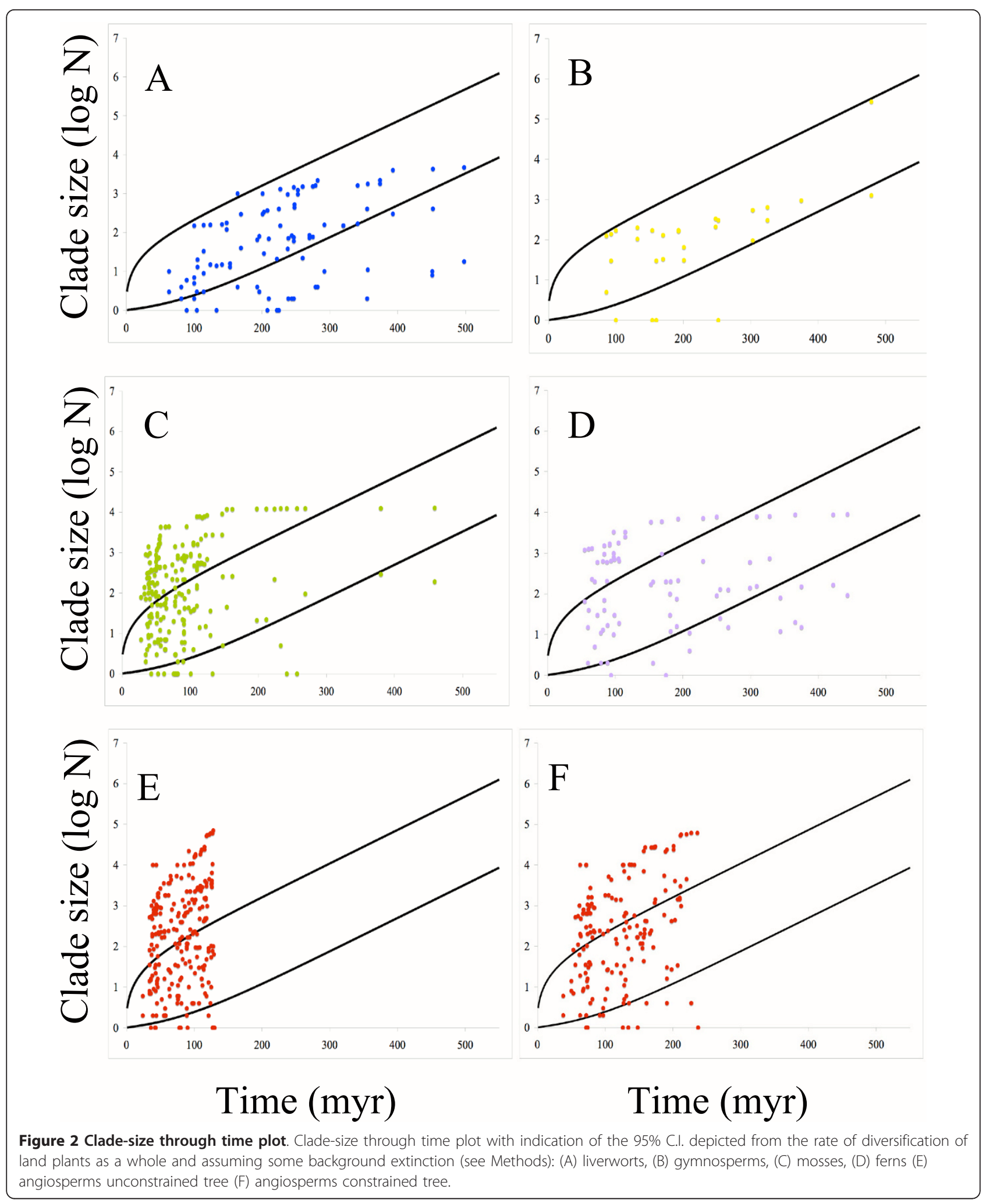


Table 1 Number of significant shifts in net diversification rate (topology-based method of Moore et al.[20]) with indication of cool (black) and warm (bold) climate modes of the Phanerozoic [21]

\begin{tabular}{|c|c|c|c|c|c|c|c|c|c|c|c|c|c|c|c|c|}
\hline \multirow{2}{*}{$\begin{array}{l}\text { Climate modes } \\
\text { Angiosperms }\end{array}$} & \multicolumn{2}{|c|}{$0-54$} & \multicolumn{2}{|c|}{$55-105$} & \multicolumn{2}{|c|}{$106-183$} & \multicolumn{2}{|c|}{$184-252$} & \multicolumn{2}{|c|}{$253-333$} & \multicolumn{2}{|c|}{$334-420$} & \multicolumn{2}{|c|}{$421-458$} & \multicolumn{2}{|c|}{$\overline{\text { Total }}$} \\
\hline & 23 & 29 & 54 & 52 & 16 & 20 & 6 & - & - & - & - & - & - & - & 99 & 101 \\
\hline Ferns & - & - & 5 & 4 & 1 & 1 & 1 & 1 & 1 & 1 & - & 2 & 2 & - & 10 & 9 \\
\hline Mosses & 2 & 7 & 6 & 8 & 3 & 2 & - & - & - & - & - & - & - & - & 11 & 17 \\
\hline Gymnosperms & - & - & - & - & 1 & 1 & - & - & - & - & - & - & - & - & 1 & 1 \\
\hline Liverworts & - & - & - & - & 2 & 1 & 5 & 4 & 4 & 4 & 2 & 1 & 1 & 1 & 14 & 11 \\
\hline Total & 25 & 36 & 65 & 64 & 23 & 25 & 12 & 5 & 5 & 5 & 2 & 3 & 3 & 1 & 135 & 139 \\
\hline
\end{tabular}

Bold number columns correspond to periods of rate increases. Time unit is Mya (million years ago). For each lineage the bottom row (italics) corresponds to the constrained tree.

gymnosperms and higher net diversification rates across monocots were recovered.

\section{Discussion and Conclusion}

By combining data for all families of land plants we are now able to clarify the picture of their evolution through geological times. Lineages of extant gymnosperms radiated in the Permian and experienced a decrease in diversification rate towards the end of the Jurassic (analysis with unconstrained tree) or early Cretaceous (analysis with constrained tree), during a cool climate mode. Although their early history may have involved various lineage replacements associated with the evolution of new ecosystems $[25,26]$, we found that the slowdown in diversification of gymnosperms took place in the same period as liverworts while mosses were diversifying intensely, pointing towards a role of climate in determining such patterns.

In this study we were also able to evaluate the diversification dynamics of all families of mosses within a phylogenetic framework for the first time. Our analyses converge to show that the diversification rate of this group experienced an important acceleration in the Cretaceous, potentially 'replacing' the diversity of gymnosperms and liverworts. This occurred during a warm climate mode when tropical habitats were undergoing

Table 2 LASER analysis using a constant-rate birth-death model with no extinction $(a=0)$ against variable-rates models with 2 and 3 rates $(r)$ and 1 or 2 time shifts given for best fitting model (ts; time unit is million years ago)

\begin{tabular}{|c|c|c|c|}
\hline & Birth-death model $(a=0)$ & 2-rates model $(\mathrm{r} 1, \mathrm{r} 2, \mathrm{ts})$ & 3-rates model $(r 1, r 2, r 3, t s 1, t s 2)$ \\
\hline \multicolumn{4}{|c|}{ Angiosperms } \\
\hline AIC & 274.8786 & -6.7234 & -43 \\
\hline Delta AIC & 0 & 281.602 & 317.40126 \\
\hline Ts1 & & & 27.53 \\
\hline Ts2 & & & 52.43 \\
\hline \multicolumn{4}{|l|}{ Ferns } \\
\hline AIC & 233.6887 & 232.7399 & 231.2457 \\
\hline Delta AIC & 0 & 0.9488 & 2.443 \\
\hline Ts1 & & & 60.02 \\
\hline Ts2 & & & 106.39 \\
\hline \multicolumn{4}{|l|}{ Mosses } \\
\hline AIC & 388.785 & 306.4588 & 301.9242 \\
\hline Delta AIC & 0 & 82.3262 & 86.8608 \\
\hline Ts1 & & & 35.19 \\
\hline Ts2 & & & 132.65 \\
\hline \multicolumn{4}{|c|}{ Gymnosperms } \\
\hline AIC & 113.2583 & 107.9801 & 109.1307 \\
\hline Delta AIC & 0 & 5.2782 & 4.1276 \\
\hline Ts & & 153.76 & \\
\hline \multicolumn{4}{|l|}{ Liverworts } \\
\hline AIC & 416.5246 & 365.2789 & 360.1666 \\
\hline Delta AIC & 0 & 51.2457 & 56.358 \\
\hline Ts1 & & & 99.52 \\
\hline Ts2 & & & 183.89 \\
\hline
\end{tabular}




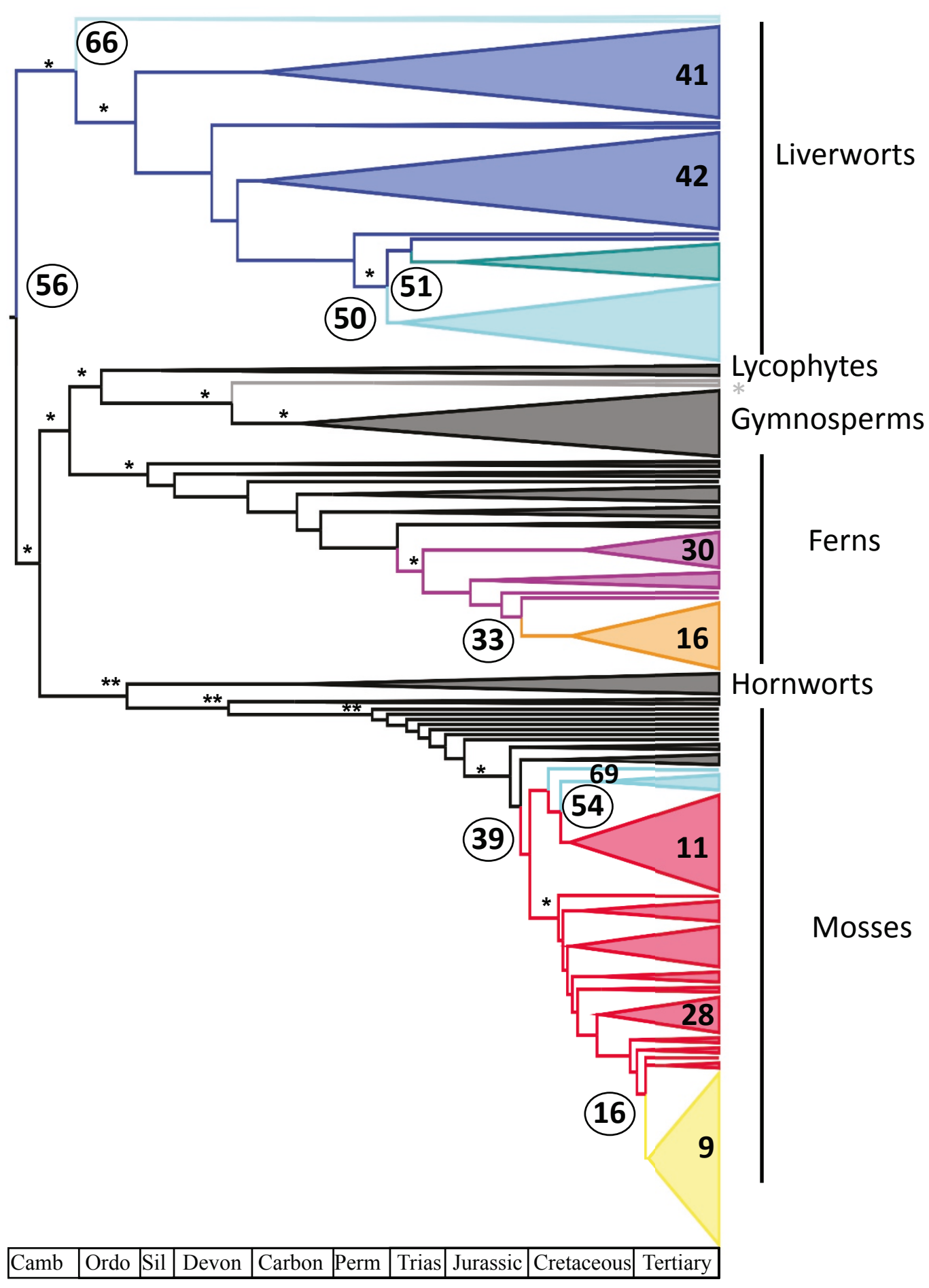

Figure 3 MEDUSA chronogram. Diversification chronogram with rate shifts located using MEDUSA [24] for different groups of land plants. Numbers correspond to the rate shifts located by MEDUSA being the numbers in increasing order from the highest to lowest net diversification rate (see Additional file 5). Different colours indicate different net diversification rates found in the tree. Boostrap support for the main nodes are indicated with one asterisk (> 70\%) and two asterisk (50\%-70\%). Angiosperms (grey asterisk) have been simplified for this figure. 
expansion. Significantly, it also corresponds to the origin of the angiosperms according to Brenner [18], or to the origin of major groups of angiosperms (asterids, rosids) as found on our unconstrained analysis and as suggested by previous studies [27]. In this sense, mosses have diversified at the same period as the one reported for fern as "the shadow of angiosperms". It is important to note that the Cretaceous could be divided in three main intervals with regards to vegetation and climate: i) "Early" Cretaceous (ca. Berriasian-Barremian) with few angiosperms, probably no closed canopy angiosperm forests, largely dry climates at low palaeolatitudes; ii) mid-Cretaceous (ca. Aptian-Santonian/Campanian), where we observe the rapid diversification of angiosperms, with presence of some angiosperm-dominated forests but still no tropical everwet forests at low palaeolatitudes; and iii) "Late" Cretaceous (ca. Campanian-Maastrichtian), where we see an early development of angiosperm dominated forests, possibly with everwet forests in low palaeolatitudes of the Old World, and perhaps also in the New World [14]. This is then followed by iv) the Early Cenozoic, when temperatures were warm and climate wet-and where there is strong evidence of widespread tropical-sub-tropical warm wet forests [14]. We found that all six shifts in diversification for mosses (Table 1 ) fall within this last two intervals (i.e. 75, 69, 64, 57, 43 and 37 mya; see details in Additional files 3), pointing to the importance of both warm temperatures and wet climate for the rise of moss diversity.

According to our analyses, mosses were not the only group to have diversified in the shadow of angiosperms: ferns have also radiated in a period that coincides with the rise of angiosperms. Such a pattern, had previously been reported [28]. Here, we find further support for this hypothesis of diversification in the shadow of angiosperms, identifying a significant increase in diversification during the warmest period of the Cretaceous, and decrease during the coolest period of the Tertiary (see Figure 1). More specifically, three out of the five rate shifts (Table 1) fall within interval iii) above of the Cretaceous, when climate was warm and wet.

Finally, we found that angiosperm diversity has accumulated sharply in recent time (as shown by the LTT plots), but diversification decreased in the coolest period of the Tertiary (Figure 1). This is in agreement with the idea that angiosperms have outcompeted and outnumber gymnosperms and free-sporing plants $[29,30]$. Subsequently, ferns (especially polypods $[28,31]$ ) and mosses [32] opportunistically diversified in the ecological niches provided by the angiosperms as the climate became warmer and more humid. In this sense, our study favours the "successive replacement" of ancestral lineages [14].

\section{Methods \\ Phylogeny}

We put together phylogenetic data for at least one representative of each of the 706 currently accepted families of land plants (Additional file 1). Our dataset was assembled using plastid $r b c L, a t p B$ and rps4 genes, as well as $18 S$ and $26 S$ nuclear ribosomal regions (hereafter $18 S$ rDNA and $26 S$ rDNA). We downloaded sequences from GenBank when available and filled some of the gaps by sequencing missing taxa when we were able to obtain suitable material (Additional file 1). DNA extraction and PCR amplification used standard protocols and primers for nuclear and plastid genes from Nickrent and Starr [33] and Cox et al. [34]. We sequenced the $18 S$ rDNA for 22 angiosperms and 13 mosses, $r b c L$ for two angiosperms, 10 mosses and one liverwort, and $a t p B$ for 39 mosses, two liverworts, one hornwort, and 18 angiosperms (Additional file 1). In total we produced a 6,950 base pairs data matrix consisting of 699 families (including four outgroups) with $65 \%$ of data presence. Only one gene could be obtained for 55 of these 699 families (Additional file 1). Streptophytes and Chlorophytes were used as the outgroup.

Due to the large size of the matrix, maximum likelihood analyses were performed in RAxML [35] using 200 bootstrap replicates and GTR+GAMMA model, as selected by ModelTest [36]. Divergence times were calculated using penalized likelihood in r8s [37] and the smoothing parameter $($ smooth $=1000)$ was calculated by cross-validation. We calibrated the chronogram with the age of eudicots at 121 mya, corresponding to the appearance of the tricolpate pollen grain typical of this clade [38]. We used a further sixteen calibration points as minimum constrains, plus a maximum age of $725 \mathrm{Ma}$ [39] for the root of the tree (Marchantiopsida, Monilophytes, Mosses, Seed plants, Annonaceae, Calycanthaceae, Hedyosmum, Lauraceae, Magnoliaceae, Meliosma, Menispermaceae, Nelumbaceae, Nymphaceae, Platanaceae, Trochodendron, Winteraceae, Additional file 6). Confidence intervals (C.I.) for divergences times were calculated by repeating the dating procedures in $\mathrm{r} 8 \mathrm{~s}$ using 100 bootstrapped matrices produced in RAxML [35]. The dating procedure was repeated constraining the age of angiosperms to a maximum of $130 \mathrm{Ma}$ following Brenner [18], i.e. "constrained tree".

\section{Diversification tests}

We examined diversification through time using several methods.

Firstly, we plotted the number of lineages through time (hereafter LTT plots) for each major subclade of land plants using the APE 1.8 package [40]. 
Secondly, to take into account extinction rates we used the approach of Magallón and Sanderson [19]. For time intervals of one million year, we calculated net diversification rates under a relative high level of background extinction (0.9 using equation 10 of Magallón and Sanderson [19].

Thirdly, we applied a topological-based test of diversification. Diversification rate shifts were calculated using the $\Delta 1$ statistics of Moore et al. [20] as implemented by Bouchenak-Khelladi et al. [41] in ApTreeshape [42] using 0.05 significance level as the cut-off point. This test uses the tree but also takes into account the total number of species per family (Table 1 ).

Fourthly, we used a test of diversification that takes into account branch lengths, i.e. the elapsed time between the nodes of the family-level tree, LASER [23]. Using the Akaike Information Criterion (AIC), LASER can compare models with various rates of diversifications (yule model with rates $r$ ) against the null expectation of a constant rate (birth-death model with no extinction). LASER also allows to identify at which points in time a given rate shift occurred (ts). LASER was applied to all major subclades.

Fifthly, we tested for multiple shifts in birth and death rates using a stepwise approach implemented in MEDUSA until improvement in AIC score was < 4 [24]. Net diversification rates together with relative extinction rates and AIC improvements were retrieved (Additional file 5).

Also, to comply with other phylogenetic analyses that have combined more genes but for fewer taxa, we also re-ran the analyses above with the following two modifications. First 11 families for which we could not obtain any DNA data (i.e., five families of liverworts, three of mosses, and three of angiosperms; Additional file 1) were placed in the DNA-based phylogenetic tree using taxonomic information following Crosby et al. [8], Buck and Goffinet [9], Stevens [13], Heinrichs et al. [7] and Smith et al. [11] (see Additional file 2). Although this procedure is suboptimal, it allowed us to perform diversification tests on a complete-family level tree. Second we enforced hornworts and lycophytes to be sister to vascular plants $[15,16]$ plus we set the maximum age for angiosperms to $130 \mathrm{Ma}$ (following Brenner [18]; our "constrained tree"). Results were compared for the constrained vs. unconstrained topologies. Finally, we compared these diversification profiles and metrics against the distribution of the climate modes of the Panerozoic following Frakes et al. [21], as well as the global temperature model of Scotese [22].

\section{Additional material}

Additional file 1: Taxa and GenBank accession numbers with new sequences generated for this study in bold. Families for which DNA data could not be obtained are indicated in italics.
Additional file 2: Chronogram of the unconstrained tree. Numbers after family name are species number considered for our analysis following Stevens [13] for angiosperms and gymnosperms, Crosby et al. [8] and Buck and Goffinet [9] for mosses, Smith et al. [11] for ferns and Stotler et al. [43] for liverworts. The $x$ axis indicate time in million years. The placement of 11 families in which no molecular data could be collected are indicated; they were connected to node numbers as

follows: 1 - Monocarpaceae, 2 - Sandeothallaceae, 3 - Chonecoleaceae, 4 - Grolleaceae, 5 - Trichotemnomaceae, 6 - Viridivelleraceae, 7 -

Microtheliaceae, 8 - Sorapillaceae, 9 - Hapthantaceae, 10 -

Balanophoraceae and 11 - Rafflesiaceae.

Additional file 3: Number of significant shift in net diversification rate (topology-based method of Moore et al. [20]) with indication of cool (grey) and warm (black) temperatures of the Phanerozoic [22]. Bold number columns correspond to periods of rate increases. Time unit is Mya (million years ago). For each lineage the bottom row (italics) corresponds to the constrained tree.

Additional file 4: LASER analysis for the constrained tree using a constant-rate birth-death model with no extinction $(a=0)$ against variable-rates models with 2 and 3 rates $(r)$ and 1 or 2 time shifts given for best fitting model (ts; time unit is million years ago).

Additional file 5: Diversification rate shift retrieved from MEDUSA [24]. Numbers on the first column correspond to the net diversification rate from highest to lowest and are depicted on Figure 3. Nonangiosperms cases are highlighted in bold, followed by the name of the group they belong to in brackets. " $r$ " are the estimates for net diversification rate, "e" are estimates for relative extinction rate, " $\triangle \mathrm{AIC}$ " is the increase on the stepwise AIC procedure and " $\triangle \mathrm{AICC}$ " is the increase when corrected for small sample size [24]. Results for the constrained tree are presented at the bottom.

Additional file 6: Minimum-age calibration points used in divergence time reconstructions [44-57].

\section{Acknowledgements}

We thank P. Crane for early review of the manuscript and helpful information, A. Newton for plant material, A. Stamatakis, Y. BouchenakKhelladi and P. Ajawatanawong for their help with bioinformatics, C. Cox and N. Bell for providing 185 sequences of mosses, M. Grundmann, A. Navarro-Gomez and S. Russel for laboratory assistance and A. Papadoupulos, J. Schnitzler, P. Rymer, L. Valente, J. Hortal, M. Romeralo and the editor and three anonymous reviewers for helpful comments. This study was supported by the Spanish Ministerio de Ciencia and the Bentham-Moxon Trust (to O.F. P), and Leverhulme Trust, NERC, Royal Society and European Research Council (to V.S).

\section{Author details}

'Division of Ecology and Evolution, Imperial College London, Silwood Park Campus, Ascot SL5 7PY, UK. ²Department of Systematic Biology, Evolutionary Biology Centre, Uppsala University, Norbyvägen 18 D, Uppsala 75236,

Sweden. ${ }^{3}$ Department of Botany, Natural History Museum, London SW7 5BD, UK. ${ }^{4}$ Albrecht-von-Haller-Institute of Plant Sciences, Georg-August University, 37073, Göttingen, Germany. ${ }^{5}$ Royal Botanic Gardens, Kew, Richmond TW9 3DS, UK.

\section{Authors' contributions}

OFP carried out the lab work, assembled the data and performed the analyses. OFP, HS and VS designed the study. JH provided crucial material and information. OFP, HS and VS coordinated the study and wrote the manuscript. All authors read and approved the final manuscript.

Received: 3 May 2011 Accepted: 21 November 2011 Published: 21 November 2011

\section{References}

1. Pounds JA, Fogden MPL, Campbell JH: Biological response to climate change on a tropical mountain. Nature 1999, 398:611-615. 
2. Parmesan $\mathrm{C}$, Yohe $\mathrm{G}$ : A globally coherent fingerprint of climate change impacts across natural systems. Nature 2003, 421:37-42.

3. Root TL, Price JT, Hall KR, Schneider H, Rosenzweig C, Pounds JA: Fingerprints of global warming on wild animals and plants. Nature 2003, 421:57-60

4. Wignall PB: Causes of mass extinctions. In Extinctions in the history of life. Edited by: Taylor PD. Cambridge University Press; 2004:151-174.

5. Wellman CH, Osterhoff PL, Mohiuddin U: Fragments of the earliest land plants. Nature 2003, 425:282-285.

6. Steemans P, Le Herisse A, Melvin J, Miller MA, Paris F, Verniers J, Wellmann $\mathrm{CH}$ : Origin and radiation of the earliest vascular land plants. Science 2009, 324:353.

7. Heinrichs J, Gradstein SR, Wilson R, Schneider H: Towards a natural classification of liverworts (Marchantiophyta) based on the chloroplast gene rbcL. Crypt Bryol 2005, 26:131-150

8. Crosby MR, Magill RE, Allen B, He S: A Checklist of the Mosses. 1999 [http://www.mobot.org/MOBOT/tropicos/most/checklist.shtml].

9. Buck WR, Goffinet B: Morphology and classification of mosses. In Bryophyte Biology. Edited by: Shaw AJ, Goffinet B. Cambridge: Cambridge University Press; 2000:71-123.

10. Shaw J, Renzaglia K: Phylogeny and diversification of bryophytes. Am J Bot 2004, 91:1557-1581.

11. Smith AR, Pryer KM, Schuettpelz E, Korall P, Schneider H, Wolf PG: A classification of extant ferns. Taxon 2006, 55:705-731.

12. Starr A, Evers CA, Starr L: Biology: Concepts and Applications Without Physiology New York: Brooks/Cole Publishing; 2008.

13. Stevens PF: Angiosperm phylogeny website, v8. 2001 [http://www.mobot. org/MOBOT/research/APweb]

14. Kenrick P, Crane PR: The origin and early evolution of plants on land. Nature 1997, 389:33-39.

15. Pryer KM, Schneider H, Smith AR, Cranfill R, Wolf PG, Hunt JS, Sipes SD: Horsetails and ferns are a monophyletic group and the closest living relatives to seed plants. Nature 2001, 409:618-622.

16. Qiu $Y$, et al: The deepest divergences in land plants inferred from phylogenomic evidence. Proc Natl Acad Sci USA 2006, 103:15511-15516

17. Wang H, Moore MJ, Soltis PS, Bell CD, Brockington SF, Alexandre R, Davis CC, Latvis M, Manchester SR, Soltis DE: Rosid radiation and the rapid rise of angiosperm-dominated forests. Proc Natl Acad Sci USA 2009, 106:3853-3858

18. Brenner GJ: Evidence for the earliest stage of angiosperm pollen evolution: A paleoequatorial section from Israel. In Flowering plant origin, evolution and phylogeny. Edited by: Taylor DW, Hickey LJ. New York: Chapman 1996:91-115.

19. Magallón S, Sanderson MJ: Absolute diversification rates in angiosperm clades. Evolution 2001, 55:1762-1780.

20. Moore BR, Chan KMA, Donoghue MJ: Detecting diversification rate variation in supertrees. In Phylogenetic Supertrees: Combining Information to Reveal the Tree of Life. Edited by: Bininda-Emonds ORP. Dordrecht: Netherlands Kluwer Academic; 2004:487-533.

21. Frakes L, Francis JE, Syktus JI: Climate modes of the phanerozoic Cambridge: Cambridge Univ. Press; 1992.

22. Scotese CR: PALEOMAP Project. 2001 [http://www.scotese.com/Default. htm].

23. Rabosky DL: LASER: A Maximum Likelihood Toolkit for Detecting Temporal Shifts in Diversification Rates From Molecular Phylogenies. Evol Bioinf Online 2006, 2:257-260.

24. Alfaro ME, Santini F, Brock C, Alamillo H, Dornburg A, Rabosky DL, Carnelale G, Harmon L: Nine exceptional radiations plus high turnover explain species diversity in jawed vertebrates. Proc Natl Acad Sci USA 2009, 106:13410-13414

25. Looy CV, Brugman WA, Dilcher DL, Visscher $\mathrm{H}$ : The delayed resurgence of equatorial forests after the Permian-Triassic ecologic crisis. Proc Natl Acad Sci USA 1999, 96:13857-13862.

26. Looy CV, Twitchett RJ, Dilcher DL, Van Konijnenburg-Van JHA, Visscher H: Life in the end-Permian dead zone. Proc Natl Acad Sci USA 2001, 98:7879-7883.

27. Bell CD, Soltis DE, Soltis PS: The age and diversification of the angiosperms re-revisited. Am J Bot 2010, 97:1296-1303.

28. Schneider H, Schuettpelz E, Pryer KM, Cranfill R, Magallón S, Lupia R: Ferns diversified in the shadow of the angiosperms. Nature 2004, 428:553-557.
29. Burger WC: Why are there so many kinds of flowering plants? Bioscience 1981, 31:572-581.

30. Magallón S, Castillo A: Angiosperm diversification through time. Am J Bot 2009, 96:349-365

31. Schuettpelz E, Pryer KM: Evidence for a Cenozoic radiation of ferns in an angiosperm-dominated canopy. Proc Natl Acad Sci USA 2009, 106:11200-11205.

32. Newton AE, Wikstrom N, Bell N, Forrest NL, Ignatov MS: Dating the Diversification of the Pleurocarpous Mosses. In Pleurocarpous Mosses: Systematics and Evolution. Edited by: Newton AE, Tangney RS. CRC Press; 2007:337-366

33. Nickrent D, Starr EM: High rates of nucleotide substitution in nuclear small-subunit (18S) rDNA from holoparasitic flowering plants. J Mol Evol 1994, 39:62-70

34. Cox C, Goffinet B, Newton AE, Shaw AJ, Hedderson TAJ: Phylogenetic relationships among the diplolepidous-alternate mosses (Bryidae) inferred from nuclear and chloroplast DNA sequences. Bryologist 2000 103:224-241

35. Stamatakis A, Hoover P, Rougemont J: A Rapid Bootstrap Algorithm for the RAxML Web-Servers. Syst Biol 2008, 75:758-771.

36. Posada D, Crandall KA: Modeltest: testing the model of DNA substitution. Bioinformatics 1998, 14:817-818.

37. Sanderson MJ: r8s: inferring absolute rates of molecular evolution and divergence times in the absence of a molecular clock. Bioinformatics 2003, 19:301-303.

38. Doyle JA, Hotton CL: Diversity of early angiosperm pollen in a cladistic context. In Pollen and spores. Edited by: Blackmore S, Barnes A. Oxford: Clarendon Press; 1991:169-195.

39. Zimmer A, Lang D, Richardt S, Frank W, Reski R, Rensing R: Dating the early evolution of plants: detection and molecular clock analyses of orthologs. Mol Genet Genom 2007, 278:393-402.

40. Paradis E, Claude J, Strimmer K: APE: Analyses of Phylogenetics and Evolution in R language. Bioinformatics 2004, 20:289-290

41. Bouchenak-Khelladi Y, Verboom GA, Hodkinson TR, Salamin N, Francois O, Chonghaile GN, Savolainen V: The origins and diversification of C4 grasses and savanna-adapted ungulates. Global Change Biol 2009, 1-21.

42. Bortolussi N, Durand E, Blum MGB, Francois O: ApTreeshape: a statistical analysis of phylogenetic treeshape. Bioinformatics 2006, 22:363-364.

43. Stotler RE, Crandall-Stotler BJ: Bryophytes. 2011 [http://bryophytes.plant.siu. edu/].

44. Chesters KIM: Some plant remains from the Upper Cretaceous and Tertiary of West Africa. Ann Mag Nat Hist 1955, 12:498-504.

45. Crane PR, Friis EM, Pedersen KR: Palaeobotanical evidence on the early radiation of magnoliid angiosperms. Plant Syst Evol 1994, 8:51-72.

46. Dilcher DL, Crane PR: Archaeanthus: an early angiosperm from the Cenomanian of the western interior of North America. Ann Mo Bot Gard 1984, 71:351-383.

47. Magallon S, Crane PR, Herendeen PS: Phylogenetic pattern, diversity, and diversification of eudicots. Ann Mo Bot Gard 1999, 86:297-372.

48. Friis EM, Eklund H, Pedersen KR, Crane PR: Virgininanthus calycanthoides gen. et sp. nov.: a calycanthaceous flower from the Potomac Group (Early Cretaceous) of eastern North America. Int J Plant Sci 1994, 155:772-785.

49. Friis EM, Pedersen KR, Crane PR: Angiosperm floral structures from the Early Cretaceous of Portugal. Plant Syst Evol 1994, 8:31-49.

50. Friis EM, Pedersen KR, Crane PR: Fossil evidence of water lilies (Nymphaeales) in the Early Cretaceous. Nature 2001, 410:356-360.

51. Manchester SR, Crane PR, Dilcher DL: Nordenskioldia and Trochodendron (Trochodendraceae) from the Miocene of Northwestern North America. Bot Gazette 1991, 152:357-368.

52. Doyle JA, Hotton CL, Ward JV: Early Cretaceous tetrads, zonasulcate pollen, and Winteraceae. I. Taxonomy, morphology, and ultrastructure. Am J Bot 1990, 77:1544-1557.

53. Doyle JA: Early Cretaceous tetrads, zonasulcate pollen, and Winteraceae. II. Cladistic analysis and implications. Am J Bot 1990, 77:1558-1568.

54. Heinrichs J, Hentschel J, Wilson R, Feldberg K, Schneider H: Evolution of leafy liverworts (Jungermanniidae, Marchantiophyta): estimating divergence times from chloroplast DNA sequences using penalized likelihood with integrated fossil evidence. Taxon 2007, 56:31-44

55. Bateman RM: Palaeobiology and phylogenetic implications of anatomically preserved Archaeocalamites from the Dinantian of Oxroad 
Bay and Loch Humphrey Bun, Scotland. Palaeontographica Abt B Palaephytol 1991, 223:1-59.

56. Miller CN: Implications of fossil conifers for the phylogenetic relationships of living families. Bot Rev 1999, 30:239-277.

57. Newton AE, Wikström N, Bell N, Forrest LL, Ignatov MS: Dating the diversification of the pleurocarpous mosses. In Pleurocarpous mosses: Systematics and Evolution. Edited by: Newton A, Tangney N. CRC Press, Boca Raton, Systematics Association; 2006:337-366.

doi:10.1186/1471-2148-11-341

Cite this article as: Fiz-Palacios et al.: Diversification of land plants: insights from a family-level phylogenetic analysis. BMC Evolutionary Biology 2011 11:341.

Submit your next manuscript to BioMed Central and take full advantage of:

- Convenient online submission

- Thorough peer review

- No space constraints or color figure charges

- Immediate publication on acceptance

- Inclusion in PubMed, CAS, Scopus and Google Scholar

- Research which is freely available for redistribution

Submit your manuscript at www.biomedcentral.com/submit
() Biomed Central 